\title{
Management of old naso-orbital fractures with ocular involvement and associated complications caused by facial trauma
}

\author{
Alia Arianti, Yunia Irawati \\ Department of Ophthalmology, Faculty of Medicine, Universitas Indonesia, Cipto Mangunkusumo Kirana Hospital, Jakarta, \\ Indonesia
}

\section{ABSTRACT}

A 14-years-old boy came with chief complaint of epiphora and history of globe rupture repair surgery due to facial trauma one year ago. Patient got complications from the trauma, including nasolacrimal duct obstruction, phthisis bulbi, enophthalmos, facial deformities, and ptosis. Multidisciplinary approach was performed simultaneously in one session surgery which included oral mucosal graft for non-irritative phthisis bulbi, silicone block implant for blowout fracture, external dacrycystorhinostomy for obstructed nasolacrimal duct, fascia lata brow suspension/frontalis sling for ptosis, and septorhinoplasty for nasal augmentation. After the surgery, symptoms of epiphora had resolved and aesthetical improvement of facial deformities was also prominent. Management of old orbital fracture poses additional challenges due to the complications that have occurred over time. Loss of functionality may seem impractical to manage because no function can be pertained. Nevertheless, it is important to still perform surgical repair for aesthetic purposes due to the psychological effect on their daily lives.

Keywords: facial trauma, management, naso-orbital fracture, ocular complications pISSN: 0853-1773• eISSN: 2252-8083 • https://doi.org/10.13181/mji.v27i1.1959 • Med J Indones. 2018;27:54-61

- Received 21 Apr 2017 • Accepted 15 Feb 2018

Corresponding author: Yunia Irawati yunia_irawati@yahoo.com

Copyright @ 2018 Authors. This is an open access article distributed under the terms of the Creative Commons Attribution-NonCommercial 4.0 International License (http://creativecommons.org/licenses/by-nc/4.0/), which permits unrestricted non-commercial use, distribution, and reproduction in any medium, provided the original author and source are properly cited. 
Facial trauma is associated with injuries to the adjacent facial bones and soft tissues, that may cause concomitant ocular injuries with vision disturbance. ${ }^{1,2}$ The most common facial bones fractures found are the mandible, nasal, midface, zygoma, and orbital with variation of incidence depends on geographic factor, injury mechanism, and study population., ${ }^{3,4}$ The most frequent causes of facial trauma with orbital involvement and ocular injuries include motor-vehicle accident (MVA), assault, falls, and sports accident, with MVA causing the most destructive trauma. ${ }^{2,4}$

Complications of facial trauma vary widely depending on the structures involved. ${ }^{5-7}$ The principle management of orbital involvement in facial trauma is to preserve the ocular function, adjacent soft tissues, orbital wall and facial bones integrity, as well as the facial aesthetic aspect. When no function can be pertained, aesthetic aspect remains the main goal of facial trauma management. The physical deformities create detrimental psychological effects, rendering an individual's capability to function normally in their daily life. Patients with complex facial fractures are also reported to have poorer longterm psycho-social well-being.,

Ideal timing of surgical intervention varies on the type of injury. Best aesthetic results for fracture repair are achieved within the first two-weeks. Prolonged periods of treatment delay may be suboptimal due to soft tissue scarring and bone callus, causing additional difficulties in its management, higher complication rate, and inferior surgical outcome. ${ }^{3,4,6,10}$

This case reported the complications of old naso-orbital fractures and ocular injuries caused by facial trauma such as enophthalmos, post traumatic nasolacrimal duct obstruction, telecanthus, and ptosis which developed due to untreated fractures. The severity of the injuries had caused the involved eye to become phthisical and also caused facial deformities which posed additional psychological problem. Despite the loss of eye function, surgical measures could still be taken. Orbital reconstruction for aesthetic purpose could be performed in conjunction with the dacryocystorhinostomy (DCR) for the obstructed duct and ptosis repair, in the hope of promoting this patient's quality of life. The purpose of this case was to demonstrate the surgical intervention of old naso-orbital fractures with ocular involvement caused by facial trauma, the challenges of the management, and the importance of aesthetic repair on patient's quality of life.

\section{CASE REPORT}

A 14-years-old boy came with chief complaint of epiphora and history of globe rupture repair surgery due to facial trauma one year ago. General examination showed the presence of facial and saddle nose deformities. From the ophthalmological examination, the right eye was within normal limit. The left eye was found to be phthisical, enophthalmos, hypoglobus, with ptosis of the eyelid (Figure 1). Eyelid examination revealed no levator action and vertical palpebral fissure, with horizontal palpebral fissure of 22 $\mathrm{mm}$. There was not enough orbital volume of the left eye when evaluated using eye prosthesis. The intraocular pressure was low with quite conjunctiva, ocular motility restriction to all directions, visual acuity of no light perception, and discontinuity of the inferior orbital rim with no crepitation with quite conjunctiva. Corneal sensibility was still positive. The lacrimal sac was still palpable with slight redness, but no discharge was found on lacrimal sac massage. The anel test was negative and probing test showed a hard stop of the lacrimal system. No left facial hypesthesia was found. The patient was assessed with post traumatic nasolacrimal duct obstruction of the left eye due to nasal bone fracture, traumatic eyelid ptosis of the left eye, impure blow out fracture of the left eye, telechantus, and phthisical left eye.

The planned surgical procedures for this patient were a combination of dacryocystorhynostomy (DCR) with silicone tube insertion, cantholysis-canthopexy, and canthoplasty, oral mucosal graft of the left eye, fascia lata brow suspension/frontalis sling, and repair of the blow-out fracture using silicone block in general anesthesia together with septorhinoplasty procedure by ear, nose and throat (ENT) department.

Preoperative assessment was performed using eye prosthesis in place because the eye was phthisical and enophthalmos, making it difficult 


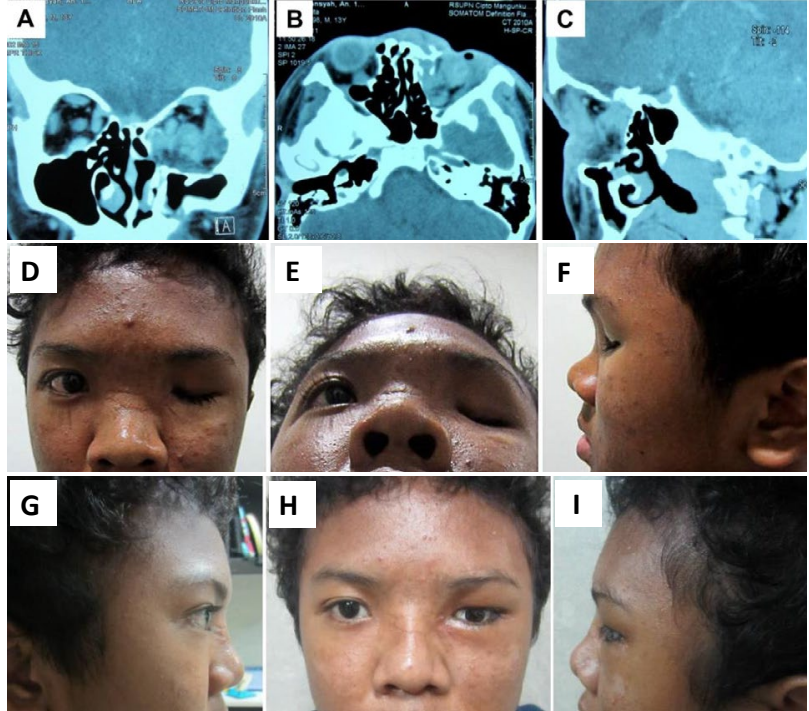

Figure 1. A) coronal; B) axial; C) sagital orbital CT scan images revealing phthisical left eye with orbital medial wall destruction, linier fracture of superior and inferior orbital wall, nasal and sphenoid bone of the left eye; D) ptosis of the eyelid and telecanthus; E) enophthalmos; F) saddle nose deformity in preoperative picture; G, H and I) Three-week post-operative pictures

to assess the eyelid function. Examination using eye prosthesis showed the levator action of the left eye was $2 \mathrm{~mm}$. Telechantal distance was 44 $\mathrm{mm}$ with left eye horizontal palpebral fissure of 22 $\mathrm{mm}$, and right eye horizontal palpebral fissure of $24 \mathrm{~mm}$. The right eyelid examination was within normal limit with margin-reflex distance (MRD) of $4 \mathrm{~mm}$, margin-limbal distance (MLD) of $9 \mathrm{~mm}$, levator action (LA) of $15 \mathrm{~mm}$, vertical palpebral fissure of $11 \mathrm{~mm}$, skin crease of $6 \mathrm{~mm}$, and no lid lag. The orbital computed tomography (CT) scan revealed phthisical left eye with orbital medial wall destruction, linier fracture of superior and inferior orbital wall, nasal and sphenoid bone of the left eye.

The multistep surgical procedure started with oral mucosa graft to cover the cornea of the left phthisical eye (Figure 2). After conjunctival peritomy was performed, diameter of the cornea was measured and its surface was scrapped. Oral mucosal graft was obtained from the lower lip, measuring at about $2 \mathrm{~mm}$ greater in diameter than the measured cornea. The graft was then sutured to the episclera using vicryl 6.0, and later to the conjunctiva using vicryl 6.0. The exposed oral mucosa was then sutured using vicryl 6.0 in three places as well.

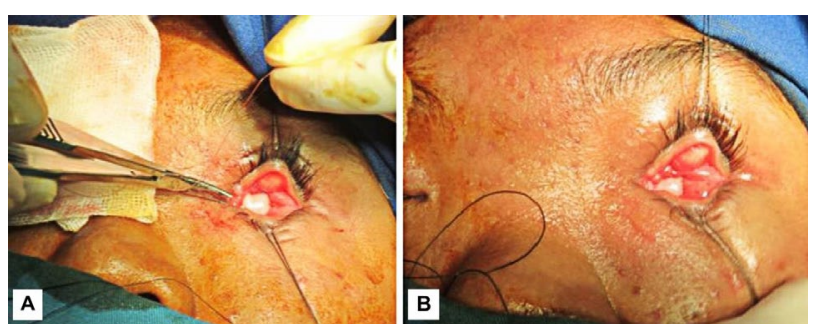

Figure 2. A and B Oral mucosal graft was sutured to the episclera and conjunctiva of the phthisical eye using vicryl 6.0

The next surgical step was to perform dacryocystorhinostomy with silicone tube insertion (Figure 3). A $20 \mathrm{~mm}$ incision was made $4 \mathrm{~mm}$ medial from the medial canthus. The skin and muscles were undermined until the periosteum was identified over the orbital rim. The periosteum was then separated from the anterior lacrimal crest while lifting the lacrimal sac from the fossa until the medial wall of fossa lacrimal could be visualized. The sac lumen was then identified using a probe via lacrimal punctum. Osteotomy was then performed using the projected guidance from the probe until nasal mucosa could be identified. A difficulty was encountered during osteotomy due to the old fractures in the nasal and medial orbital rim bone. Hard callus and impacted bone fractures posed additional challenges in making the osteotomy. The anterior flap of the lacrimal sac and nasal mucosa was then made, and topical mitomycin $\mathrm{C}$ was applied for 2 minutes. The posterior sac mucosal flap was secured to the posterior nasal flap. The silicone tube was then inserted through inferior and superior canaliculus into nasal medial concha, and simple knot was made on the edges of the tube. The anterior flap of lacrimal sac was then sutured to the anterior flap of the nasal mucosa. Finally, the skin was closed using continous subcuticular suture with prolene 6.0.

After the DCR was performed, the next step was silicone block insertion for the blow-out fracture followed by canthopexy and canthoplasty. A subciliary incision was marked 2-3 mm below the lower lashes, and incision was performed. The orbicularis muscle below was undermined until the orbital rim could be identified. Periosteum incision along the orbital rim was made, and the entrapped soft tissue was released from the fracture. After the soft tissue entrapment was released, two silicone blocks were inserted. After the implants were securely placed, the orbital septum was 

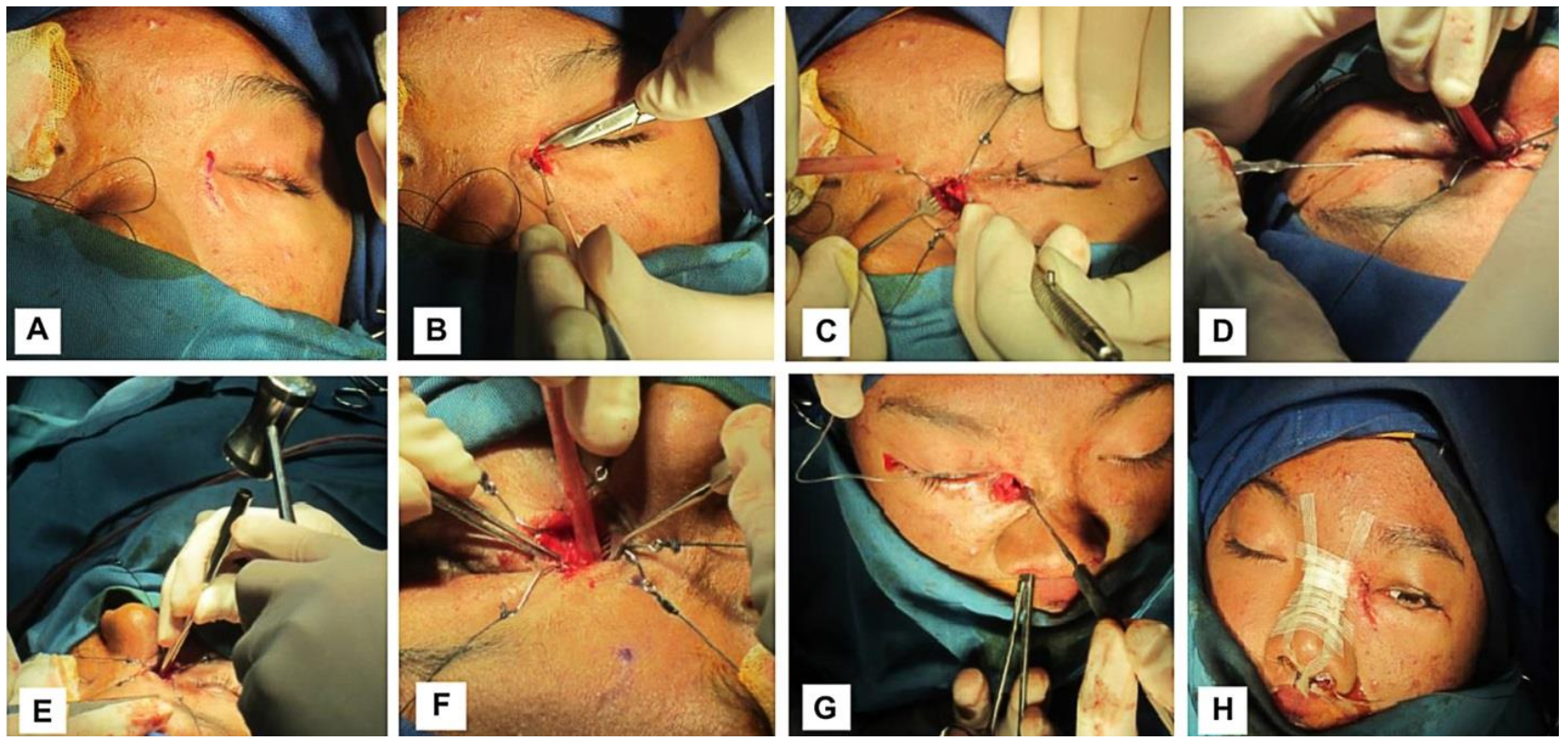

Figure 3. A) A $20 \mathrm{~mm}$ skin incision $4 \mathrm{~mm}$ from medial canthus; B) Tissue undermined to identify periosteum; C) Separation of periosteum and lacrimal sac to expose medial lacrimal fossa; D) Probing to identify sac lumen; E) Osteotomy; F) Anterior and posterior flap from both lacrimal sac and nasal mucosa were made; G) Silicone tube insertion; H) Skin incision was closed

sutured tightly using vicryl 5.0. Skin incision was closed (Figure 4). Lateral cantholysis, canthopexy, and canthoplasty were performed. The eye prosthesis was then put in place. This procedure was performed in parallel with septorhinoplasty procedure by ENT department.

The septorhinoplasty procedure was performed using costae cartilage augmentation. Incision was made in the infra cartilage nasal area. The dorsum nasi area was undermined, nasal septum was identified, and antero-posterior tunnel was made. Posterior and inferior condrotomy were performed, and the deviated nasal bone and cartilage was taken. The graft was then put in place.

The final step of this procedure was frontalis sling with fascia lata to repair the ptosis eyelid. The procedure started with the preparation of the fascia lata. The fascia lata was taken $5 \mathrm{~cm}$ from the lateral epicondylar. A $3 \mathrm{~cm}$ incision mark was made, and incision was performed along the marked site. The tissue below the incision was undermined until fascia lata could be identified. Fascia lata was incised in $1.5 \times 3 \mathrm{~cm}$ dimension, and the wound was sutured layer by layer using vicryl 4.0 . The incised skin was sutured using prolene 4.0. After the fascia lata was prepared, a $2 \mathrm{~mm}$ incision on the lid crease above the superior palpebra margin was performed (Figure

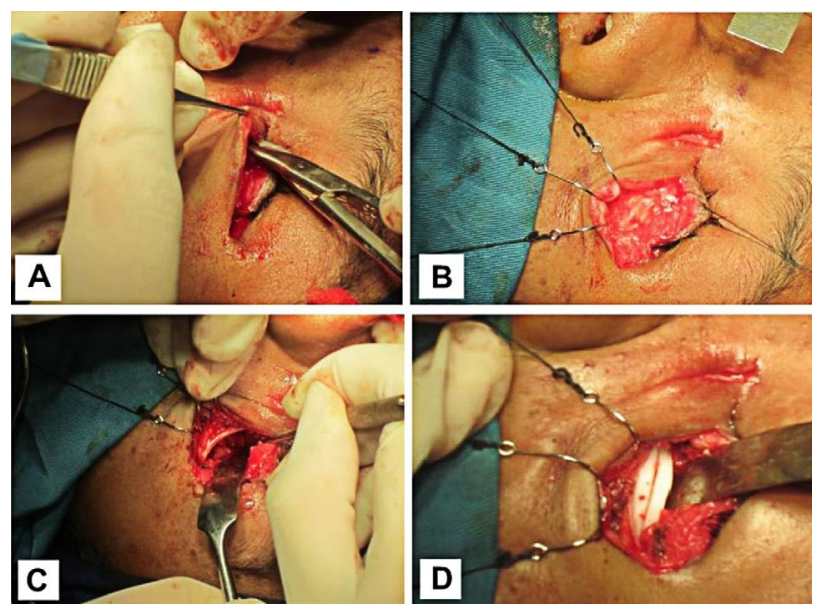

Figure 4. A) and B) Subciliary incision was made and orbicularis oculi muscle was undermined; C) Identification of the orbital floor, entrapped tissue was released; D) Silicone blocks insertion

5). The tissue was then undermined inferiorly and superiorly until tarsal could be identified. Second incision was then made in the suprabrow region, just above the brow slightly medial to the medial canthus. The tissue was undermined in perpendicular with frontalis muscle, creating a tunnel to the inferior at the superior orbital rim until the orbicularis oculi muscle was penetrated. The tunnel was then extended. The fascia lata was then divided into two parts and sutured into the 

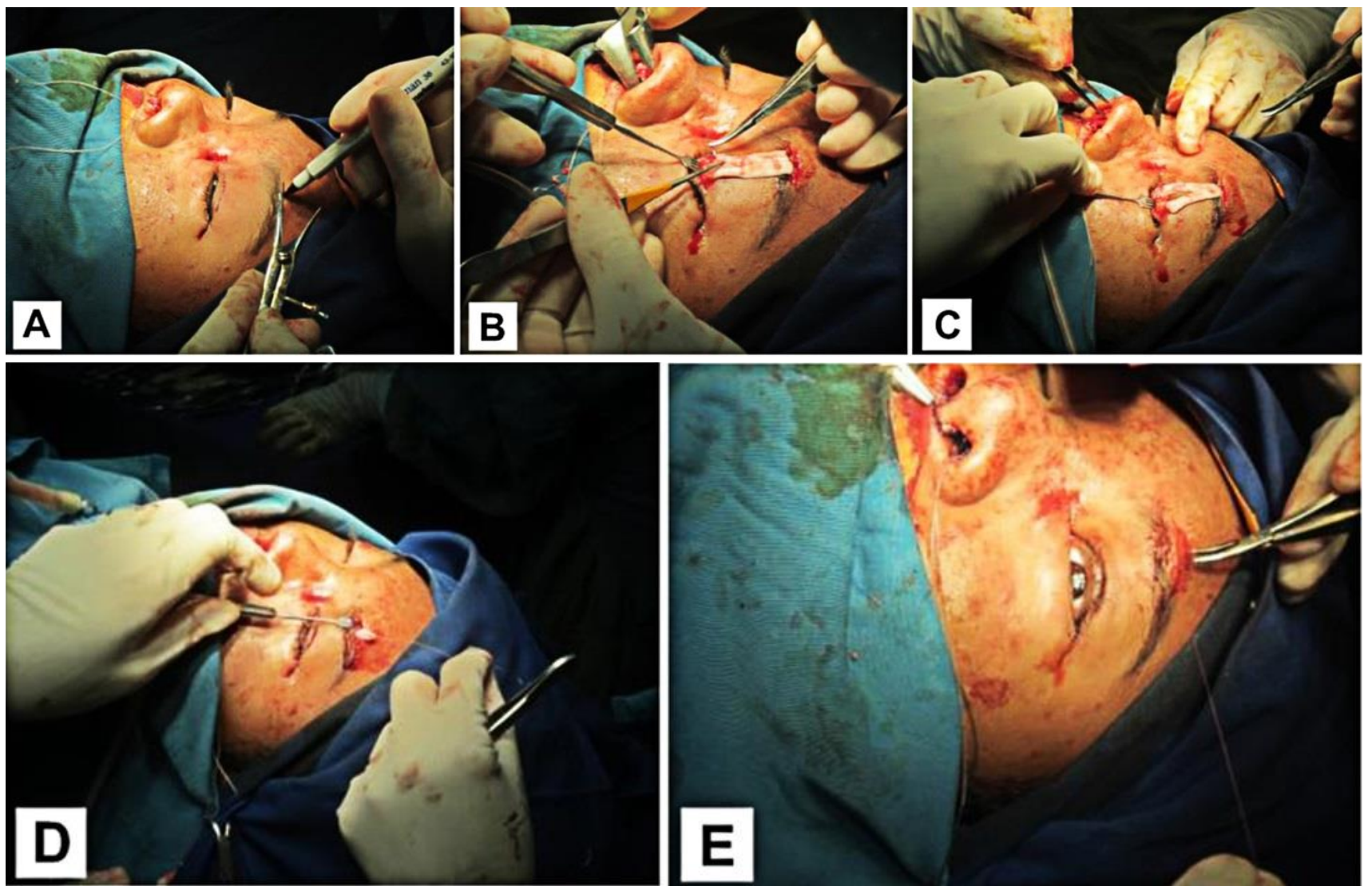

Figure 5. A) Upper lid skin crease and upper brow incision was marked; B) and C) Fascia lata inserted and sutured into the tarsal; D) Superior traction of the fascia lata through the tunnel; E) Skin incision was closed

tarsal each at three sites using prolene 6.0. Lid crease was then created using subcutaneous suture of the fascia lata into the skin using prolene 6.0 in three sites, followed by skin-to-skin suture using vicryl 6.0. The fascia lata was then guided superiorly through the tunnel and was sutured to the frontalis muscle until the height upper eyelid was adjusted. The skin incision was then closed using prolene 6.0.

On the follow up three weeks after the surgery, the patient had not experienced epiphora since the surgery. Saddle nose deformity was no longer found. The eye prosthesis was in place with good condition with no enophthalmos. Intercanthal distance decreased to $39 \mathrm{~mm}$, with horizontal palpebral fissure of the right and left eye each measuring at $27 \mathrm{~mm}$. The edema had resolved further and the left eye showed $7 \mathrm{~mm}$ of vertical palpebral fissure and lid crease of $2 \mathrm{~mm}$. Anel test was performed with positive result, showing patency of the lacrimal bypass created by DCR. Despite the slightly enophthalmos and hypoglobus left eye, the overall facial symmetry was greatly improved.
The patient felt better in terms of confidence and showed improved psychosocial well-being.

\section{DISCUSSION}

The delayed surgical treatment for nasoorbital fractures in this patient beyond period of two weeks creates certain problems in the management, additional complications, and suboptimal surgical outcome. ${ }^{3,4,6,10}$ This patient came with history of facial trauma one year ago, with naso-orbital fractures and phthsicial eye due to previous open globe rupture, which are commonly found in concordance. The unrepaired naso-orbital fractures had caused complications of saddle-nose deformity, persistent enophthalmos, telecanthus, traumatic ptosis, and post traumatic nasolacrimal duct obstruction, posing additional need for other surgical intervention. Surgical intervention could still be performed only to enhance the aesthetical appearance and to relieve the adnexal problems due to the complications. 
Ideally, fracture reposition and fixation are performed to facilitate the early healing process until the healed bone regains its adequate strength. At the time surgical intervention was performed in this patient, the healing process had reached remodeling stage. The bone fragments had joined through the healing process, making definitive repair of the fracture by reduction and internal fixation could not be performed to this patient.

The phthisical eye in this patient was due to the previous open globe injuries to the globe. Force of blunt trauma is capable of causing breakdown of eyeball integrity in its weakest structural site and intraocular disassembly due to the energy absorption.,11 Despite the emergency primary surgical repair has been performed in this case, the extensive and severity of the globe trauma made the eye to become non-functional after the trauma. The left eye had no light perception visual acuity of the left eye and low intraocular pressure, showing definite signs of phthisis bulbi of the left eye. ${ }^{12}$

Mild ocular symptoms in non-irritative phthisical eye may be treated using symptomatic treatment, and scleral shells or prosthesis can be used for cosmetic purposes. Chronic irritation and painful phthisical eyes should undergo enucleation or evisceration with orbital implantation with regard to potential long-term complications such as symphathetic ophthalmia. ${ }^{12,13}$ Non-irritative phthisical eye is better to be preserved than enucleated to maintain an adequate globe volume with superior aesthetical results than enucleated orbit with implant. In patient, the phthisical eye was relatively quiet with no inflammatory signs, and the corneal sensitivity was still present. We assessed the patient with non-irritative phthisical left eye. Therefore, neither evisceration nor enucleation was needed, and sclera shell became one of the options for cosmetic purpose in this patient.

However, the usage of sclera shell is often associated with corneal discomfort and irritation which often prevents successful wearing. A total permanent corneal cover is needed to keep the eye painless and capable of tolerating a prosthetic shell. Several procedures that can be used for corneal cover include conjunctival flap, homologous sclera, autogenous auricular cartilage, fascia lata, periosteum, split-thickness dermis, and oral/ buccal mucous membrane. ${ }^{14,15}$ Oral mucosal graft is commonly used to reconstruct the fornices of anophthalmic socket with excellent results, and might be better adjuncts than conjunctival flaps in patients with corneal sensitivity who requires sclera shell. ${ }^{13,14}$ Ma'luf et al reported superior results of oral mucosal graft for covering sensitive cornea in comparison with conjunctival flap for patients requiring scleral shells. Therefore, oral mucosal graft was the preferred approach for corneal cover in this patient which still had corneal sensitivity. ${ }^{13}$

Persistent enophthalmos in this patient was caused by unrepaired orbital blowout fracture. It also caused hypoglobus, ocular motility restriction, and discontinuity of inferior orbital rim in this patient. Entrapment of soft tissue, extraocular muscle, and innervations damage due to the fracture may be the cause. Burnstine ${ }^{16}$ divided surgical timing and management into immediate, within 2 weeks, and observation only. Indications for immediate repair include non-resolving oculocardiac reflex, a 'whiteeyed' blowout fracture, and early enophthalmos or hypoglobus. Other studies stated indication for immediate repair was evidence of muscle entrapment which might cause ischemia, fibrosis, and ultimately motility limitations, which was best performed within 48 hours. ${ }^{6}$ The most common indication for surgical repair is a large floor defect, greater than $1 \mathrm{~cm}$ in size. ${ }^{10}$

This patient ideally should undergo immediate repair of the orbital floor fracture due to early manifestation of enophthalmos, and possible entrapment although no signs of oculocardiac reflex was found. Immediate repair could not be performed due to poor general condition in the first 10 days after the initial trauma. Cole et al reported good results of orbital floor repair after 1 to 2 weeks delay of treatment allowing the orbital swelling to resolve. This delay in fracture repair caused a persistent enophthalmos. ${ }^{10}$

The surgical repair in orbital floor fracture is aimed at functional and aesthetical aspects by reconstituting defect, providing support of orbital contents, recovering ocular motility disturbance, and preventing late enophthalmos without having to concern the fragment to heal in malunited fashion. ${ }^{3,10,17}$ Implants are usually used in order to achieve the goal of orbital floor reconstruction. The ideal implant should be biocompatible and easily placed, provide a good structural support, stable, and slightly resorbable. ${ }^{17} \mathrm{~A}$ wide array of implants to choose from including allogenic implants such as 
silicone, titanium, porous polyethylene, resorbable implants, as well as autologous graft of bone or cartilage. ${ }^{18}$ Although contradiction remains among reports of advantages and disadvantages of silicone block use for orbital floor implant, recent studies showed good results with low complication rates and high patient satisfaction. ${ }^{10,18}$ Therefore, silicone block was the preferred allogenic implant used for this patient.

Saddle nose deformity, prominent telecanthus, and nasolacrimal duct obstruction were the other signs of complications found from the delay fracture repair in this patient. The abnormalities were due to unrepaired naso-orbitalethmoid fractures. Complications of naso-orbitalethmoid fractures include ocular damage, severe epistaxis, rhinorrhea, damage to the lacrimal drainage system, lateral displacement of the medial canthus, and associated orbital fractures. The medial canthal tendon inserts in medial wall, thus fractures in this area may cause displacement and telecanthus. ${ }^{19}$ The anterior and posterior limbs of the medial canthal tendon encase the nasolacrimal sac and severe damage in this area may lead to tear outflow obstruction. The lateral nasal wall also contains the nasolacrimal duct, which enters the nasal cavity through the inferior meatus. Therefore, any naso-orbito-ethmoidal fractures can result in nasolacrimal duct obstruction which interferes with lacrimal outflow. Presenting symptoms include epiphora, discharge, dacryocyctitis and conjunctivitis., ${ }^{419}$ Ali et al reported that $50 \%$ of patients with naso-orbito-ethmoidal fractures presented with swelling below the medial canthal. ${ }^{19}$

As a result of no initial fracture repair was performed, the patient came with left nasolacrimal duct obstruction. The obstruction was confirmed by negative anel test, and hard stop probing of the lacrimal system. Nasolacrimal duct obstruction secondary to naso-orbital-ethmoidal fractures is a complication found only in 5 to $10 \%$ after open reduction and internal fixation. However, the incidence climbed to $100 \%$ when the therapy was delayed for more than 2 weeks, as found in this patient. ${ }^{7}$ Early open reduction and internal fixation reduce the incidence of post traumatic nasolacrimal duct obstruction. ${ }^{19}$

Presence of nasolacrimal duct obstruction is an indication for dacryocystorhinostomy surgery (DCR) in this patient. The principles of external DCR is to create bypass of the obstructed nasolacrimal duct, forming an anastomosis of the lacrimal sac and nasal mucosa through a nasal ostium created by an external skin incision. ${ }^{20}$ The success rate for DCR procedure in managing secondary nasolacrimal duct obstruction caused by naso-orbital-ethmoid fractures was reported as high as $100 \% .^{19,21}$

External DCR was performed after the initial injury in this patient, with the fractures fragment have undergone healing process and formation of hard callus. The anatomical defect due to the fractures poses additional challenges in the procedure. Mitomycin C (MMC) application during DCR is also used to minimalize the healing process that would interfere with the expected result. Ali et al reported a high success rate of 92.8\% in similar cases performed DCR within 2 to 49 months following the initial trauma, using MMC application and intubation stent. Mitomycin $\mathrm{C}$ and silicone tube as intubation stent were used to achieve optimal DCR result. The patency of lacrimal passage was confirmed in the three weeks post-operative follow up, with positive anel test. ${ }^{19}$

The one-year delay in management of naso-orbital-ethmoid fracture had caused the fractured bones to heal and ossified. Thus, definitive repair of reduction and internal fixation could not be performed. The late nasoorbital-ethmoid fractures was augmented using septorhinoplasty procedure with costae cartilage graft in this patient in for cosmetic purpose.

Orbital trauma may also cause damages to the surrounding soft tissue, including the upper eyelid. Ptosis of the eyelid may be acquired after trauma to the orbit. Etiologies of traumatic ptosis include eyelid laceration, orbital fractures involving orbital apex or floor, orbital hemorrhage, and trauma to the levator aponeurosis. ${ }^{22}$ The possible traumatic ptosis mechanisms in this patient are due to innervation damage of the third cranial nerve (oculomotor nerve) which may happen in orbital apex and floor fracture.

Current recommendation for surgical repair of traumatic ptosis includes delaying any repair for 6 to 12 months because spontaneous regeneration and some degree of recovery may occur. After this period, surgery can be performed 
with the chosen techniques depending on the severity of ptosis and levator function recovery. Brow suspension/frontalis sling technique is chosen for ptosis with poor levator function $(<4 \mathrm{~mm})$ and most severe ptosis cases. This technique is based on the principle that frontalis muscle normally lifts the eyebrow and contributes to eyelid elevation. This action of lifting the eyelid is enhanced by connecting the frontalis muscle and eyebrow to the eyelid with a subcutaneous 'sling' using various materials. Both autoplastic or alloplastic material can be used for this technique. Autoplastic material includes fascia lata, while alloplastic material includes mersilene mash, silicone rod, or silicone sling. It is, however, generally agreed that fascia lata gives the best results. ${ }^{22}$ Our patient showed signs of severe ptosis with poor levator function of less than $4 \mathrm{~mm}$ that lasted for 12 months, which indicated the use of brow suspension/frontalis sling technique to repair the ptosis.

On the follow up, three weeks postsurgery, the patient showed improvement. There were no longer complains of epiphora which showed improved function of the lacrimal drainage system. Aesthetical improvement was also noted. The long term prognosis for this patient is good although the left eye is no longer functional. The management in this case is aimed at the aesthetical aspect. Facial deformities pose detrimental effect on patient's psychological aspect, rendering their ability to function normally on daily life. ${ }^{8}$ Patients with complex facial fractures are also reported to have poorer long-term psychosocial well-being. ${ }^{9}$ Therefore, successful surgical repair of the deformity may enhance patient's quality of life.

\section{Conflicts of Interest}

The authors affirm there is no conflict of interest in this study.

\section{REFERENCES}

1. Magarakis M, Mundinger GS, Kelamis JA, Dorafshar $\mathrm{AH}$, Bojovic B, Rodriguez ED. Ocular injury, visual impairment, and blindness associated with facial fractures: a systematic literature review. Plast Reconstr Surg. 2012;129(1):227-33.

2. Myga-Porosilo J, Skrzelewski S, Sraga W, Borowiak H, Jackowska Z, Kluczewska E. CT imaging of facial trauma. Role of different types of reconstruction. Part I - Bones. Pol J Radiol. 2011;76(1):41-51.
3. Chen C-T, Chen Y-R. Update on orbital reconstruction. Curr Opin Otolaryngol Head Neck Surg. 2010;18(4):311-6.

4. Roth FS, Koshy JC, Goldberg JS, Soparkar CNS. Pearls of orbital trauma management. Semin Plast Surg. 2010;24(4):398-410.

5. Dunkin JM, Crum AV, Swanger RS, Bokhari SA. Globe trauma. Semin ultrasound CT MR. 2011;32(1):51-6.

6. Cole P, Kaufman Y, Hollier L. Principles of facial trauma: orbital fracture management. J Craniofac Surg. 2009;20(1):101-4.

7. Nguyen M, Koshy JC, Hollier LH. Pearls of nasoorbitoethmoid trauma management. Semin Plast Surg. 2012;24(4):383-8.

8. Thakkar P, Patel JR, Sethuraman R, Nirmal N. Custom ocular prosthesis: a palliative approach. Indian J Palliat Care. 2012;18(1):78-83.

9. Girotto JA, MacKenzie E, Fowler C, Redett R, Robertson B, Manson PN. Long-term physical impairment and functional outcomes after complex facial fractures. Plast Reconstr Surg. 2001;108:312-27.

10. Cole P, Boyd V, Banerji S, Hollier LH Jr. Comprehensive management of orbital fractures. Plast Reconstr Surg. 2007;120 (Suppl. 2):57S-63S.

11. Lindsey JL, Hamill MB. Scleral and corneoscleral injuries. In: Kuhn F, Pieramici DJ, editors. Ocular Trauma Principles and Practice. New York: Thieme; 2002. p. 111-22.

12. Schmack I, Volcker HE, Grossniklaus HE. Phthisis bulbi. In: Levin LA, Albert DM, editors. Ocular Disease Mechanism and Management. USA: Saunders Elsevier 2010. p. 415-23.

13. Ma'luf RN, Awwad ST. Mucous membrane graft versus gunderson conjunctival flap for fitting a scleral shell over a sensitive cornea. Ophthal Plast Reconstr Surg. 2005;21(5):356-8.

14. Mai C, Bertelmann E. Oral Mucosal Graft: Old technique in new light. Ophthalmic Res. 2013;50(2):91-8.

15. Aggarwal H, Singh RD, Kumar P, Gupta SK, Alvi HA. Prosthetic Guidelines for ocular rehabilitation in patients with phtisis bulbi: a treatment-based classification system. J Prosthet Dent. 2014;111(6):525-8.

16. Burnstine M. Clinical recommendations for repair isolated orbital floor fractures: an evidence-based analysis. Ophthalmology. 2002;109(7):1207-10.

17. Rinna C, Ungari C, Saltarel A, Cassoni A, Reale G. Orbital floor restoration. J Craniofac Surg. 2005;16(6):968-72.

18. Prowse SJ, Hold PM, Gilmour RF, Pratap U, Mah E, Kimble FW. Orbital floor reconstruction: a case for silicone. A 12 years experience. J Plast Reconstr Aesthet Surg. 2010;63(7):1105-9.

19. Ali MJ, Gupta H, Honavar SG, Naik MN. Acquired nasolacrimal duct obstructions secondary to nasoorbito-ethmoidal fractures: patterns and outcomes. Ophthal Plast Reconstr Surg. 2012;28(4):242-5.

20. Nerad JA. Diagnosis and management of the patient with tearing. In: Nerad JA, editor. Techniques in Ophthalmic Plastic Surgery. Cincinnati: Saunders Elsevier; 2010. p. 260-96.

21. Becelli R, Renzi G, Mannino G, Cerulli G, Lannetti G. Post traumatic obstruction of lacrimal pathways: a retrospective analysis of 58 consecutive naso-orbitoethmoid fractures. J Craniofac Surg. 2004;15(1):29-33.

22. Finsterer J. Ptosis: causes, presentation, and management. Aesth Plast Surg. 2003;27(3):193-204. 